\title{
The Effect of Storage-Induced Changes in Ammonia Borane on Hydrogen Release during Its Low-Temperature Thermolysis
}

\author{
Oxana V. Komova ${ }^{1}$, Olga V. Netskina ${ }^{1,2, * \mathbb{C}}$, Anna M. Ozerova ${ }^{1}$, Galina V. Odegova ${ }^{1}$, \\ Sergei S. Arzumanov ${ }^{1,2}$ and Valentina I. Simagina ${ }^{1}$ \\ 1 Boreskov Institute of Catalysis SB RAS (BIC SB RAS), 630090 Novosibirsk, Russia \\ 2 Department of Natural Sciences, Novosibirsk State University, 630090 Novosibirsk, Russia \\ * Correspondence: netskina@catalysis.ru; Tel.: +7-383-330-74-58
}

Received: 28 June 2019; Accepted: 1 August 2019; Published: 4 August 2019

\begin{abstract}
In this paper, low-temperature solid-state processes of the dehydrogenation of ammonia borane $\left(\mathrm{NH}_{3} \mathrm{BH}_{3}, \mathrm{AB}\right)$ samples of different purity are compared under the conditions of isothermal heating at $100^{\circ} \mathrm{C}$, as well as in the course of thermal analysis which was also carried out at different rates of heating. The composition of boron-containing impurities was studied by attenuated total reflection Fourier transform infrared spectroscopy (ATR FTIR) and ${ }^{11} \mathrm{~B}$ magic angle spinning nuclear magnetic resonance $\left({ }^{11} \mathrm{~B}\right.$ MAS NMR). Accumulation in $\mathrm{AB}$ of three- and four-coordinated borate anions upon contact of hydride with air moisture is established. The apparent activation energies were calculated from thermal analysis data, and found to decrease from 174 to $163 \mathrm{~kJ} / \mathrm{mol}$ as the AB purity decreased from $93 \%$ to $79 \%$. This showed itself in a shortening of the induction period during the $\mathrm{AB}$ thermolysis under isothermal conditions. The prospects of using the thermal analysis for estimating $\mathrm{NH}_{3} \mathrm{BH}_{3}$ reactivity are discussed.
\end{abstract}

Keywords: hydrogen storage; ammonia borane; purity; borates; thermolysis; Kissinger equation; activation energy

\section{Introduction}

With the progress in the development of hydrogen economy in the last decade, there has been much interest in ammonia borane [1,2]. As follows from the literature, the main competitive advantages of ammonia borane $\left(\mathrm{AB}, \mathrm{NH}_{3} \mathrm{BH}_{3}\right)$, as compared with other hydrides, consist in the following: the compound is a solid air-stable crystalline substance containing $19.6 \mathrm{wt} \%$ of hydrogen, which corresponds to three equivalents of $\mathrm{H}_{2}$; the compound is capable of releasing the first equivalent of relatively pure $\mathrm{H}_{2}$ in low-temperature thermolysis $\left(\sim 100^{\circ} \mathrm{C}\right)(1)$. The release of the second equivalent of $\mathrm{H}_{2}$ (2) taking place at around $150^{\circ} \mathrm{C}$ is, however, complicated by the formation of toxic boron-containing gases [3,4]. The third stage of the $\mathrm{NH}_{3} \mathrm{BH}_{3}$ thermolysis (3) is beyond the researchers' interest because it requires the use of high temperatures [4].

$$
\begin{gathered}
x \mathrm{NH}_{3} \mathrm{BH}_{3} \rightarrow\left[\mathrm{NH}_{2} \mathrm{BH}_{2}\right]_{x}+x \mathrm{H}_{2} \uparrow \sim 100{ }^{\circ} \mathrm{C} \Delta \mathrm{m}=6.5 \mathrm{wt} \% \\
{\left[\mathrm{NH}_{2} \mathrm{BH}_{2}\right]_{x} \rightarrow[\mathrm{NHBH}]_{x}+x \mathrm{H}_{2} \uparrow \sim 150{ }^{\circ} \mathrm{C} \Delta \mathrm{m}=13 \mathrm{wt} \%} \\
{[\mathrm{NHBH}]_{x} \rightarrow \mathrm{BN}+x \mathrm{H}_{2} \uparrow>500{ }^{\circ} \mathrm{C} \Delta \mathrm{m}=19.6 \mathrm{wt} \%}
\end{gathered}
$$

These Equations are rather often used for an overall description of $A B$ dehydrogenation, but they do not reflect the complexity of the process [5-7]. For the pathways of $A B$ conversion, the structure of the intermediate compounds depends on the conditions used to carry out the process. So far, 
no mathematical modeling of the release of the first equivalent of $\mathrm{H}_{2}$ has been made, which would take into account the multi-stage character of the process and the parameters of individual stages. One of the universal and widely employed approaches used to estimate $\mathrm{AB}$ reactivity and determine apparent energies of activation and effective rate constants is the Kissinger Equation (4), which is used for the description of the data of thermal analysis at different heating rates [8]:

$$
-\ln \left(\frac{\beta}{T_{m}^{2}}\right)=\ln \left(\frac{A_{0} \cdot R}{E_{a}}\right)-\frac{E_{a}}{R \cdot T_{m}}
$$

where $A_{0}$ is a pre-exponential factor $\left(\mathrm{min}^{-1}\right), E_{a}$ is apparent activation energy $(\mathrm{kJ} / \mathrm{mol}), \beta$ is the rate of heating $\left(\mathrm{K} \cdot \mathrm{min}^{-1}\right)$, and $T_{m}$ is the temperature at the point of the maximum $(\mathrm{K})$ in a differential thermal analysis (DTA) and differential scanning calorimetry (DSC) curve. It has been shown, for one and the same sample of $\mathrm{AB}$, that the values obtained by the Kissinger Equation are in good agreement with the results obtained by other methods used for the description of topochemical processes (Ozava-Flynn-Wall, ASTM) [9]. However, for the first stage of the AB thermolysis (1), the energies of activation calculated by the Kissinger Equation (4) showed a rather large scatter from 120 to $180 \mathrm{~kJ} / \mathrm{mol}$ [8-11]. Such a wide range of activation energies is in sufficiently good agreement with the conclusions made in [12], where the thermal behavior of $A B$ has been shown to be primarily determined by the method of preparation.

In describing the details of an experiment, the authors always indicate the origin of the hydride. In the case of a commercial sample, its initial purity is indicated. However, opening the container with the reagent in the air or its storage under different conditions may lead to its slow hydrolysis, worsening of the purity and accumulation of hydrolysis products. By the present time, there has been practically no information in the literature about $A B$ transformations during its storage and their influence on hydride thermal behavior [13]. On the other hand, handling $A B$ under inert conditions is not practically acceptable, since $A B$ stability and safety of its handling in the open air constitute its competitive advantages. Therefore, it is necessary to know how the decrease in AB purity will tell upon its ability to release hydrogen in the course of heating.

In this work, the reactivity of an $A B$ sample with a purity of $79 \%$ (AB 79\%), which has been stored in a periodically opened desiccator for 12 years, is compared with the reactivity of an AB sample with 93\% purity ( $\mathrm{AB} 93 \%$ ). The comparison is performed under the conditions of isothermal heating at $100{ }^{\circ} \mathrm{C}$, and under the conditions of the heating at a fixed rate $\left(1-10^{\circ} \mathrm{C} \cdot \mathrm{min}^{-1}\right)$. The composition of the formed impurities is studied by ATR FTIR and ${ }^{11} \mathrm{~B}$ MAS NMR.

\section{Results}

Despite the fact that ammonia borane is considered to have the highest air moisture stability among hydrides, it still decomposes slowly when stored for many years. Our experience shows that, in a closed container, its purity decreases by about $1 \%$ annually (based on observations over 12 years). Figure 1 shows the kinetic curves of hydrogen release from the AB sample with $93 \%$ purity, as well as the stored $\mathrm{AB}$ sample with $79 \%$ purity. The experiment was performed under isothermal conditions at the temperature of the external heating of the reactor of $100{ }^{\circ} \mathrm{C}$. The thermolysis of $\mathrm{AB}$ under such conditions has been well-studied [14-18]. Its dehydrogenation occurs by stage (1) and shows an induction period, characteristic of topochemical processes, during which destabilization of dihydrogen bonds of the $\mathrm{AB}$ crystal lattice takes place, as well as melting of $\mathrm{AB}$ and its isomerization to diammoniate diborane (DADB), and the nucleation and growth of the new phase of polyaminoborane. As expected, the yield of hydrogen from the $A B 79 \%$ sample was smaller than that from the $A B$ $93 \%$ sample. Moreover, the induction period for the less pure sample (AB 79\%) was considerably shorter, which allowed us to suggest that the products of its decomposition during storage accelerated formation of the DADB phase, which then acted as an initiator of $A B$ dehydrogenation. 


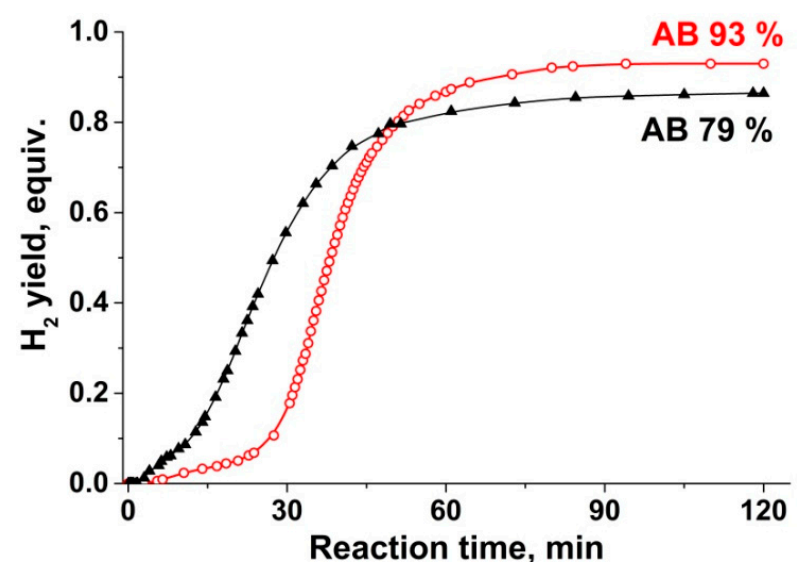

Figure 1. Release of hydrogen from samples of $\mathrm{NH}_{3} \mathrm{BH}_{3}$ having different purities. Temperature is $100{ }^{\circ} \mathrm{C}$, and the amount of the sample is $100 \mathrm{mg}$.

The ammonia borane samples were studied by ATR FTIR spectroscopy and ${ }^{11} \mathrm{~B}$ MAS NMR. The ${ }^{11} \mathrm{~B}$ MAS NMR spectra are shown in Figure 2. It is seen that both samples show an intense peak at $-27 \mathrm{ppm}$, which is in good agreement with the data for ammonia borane given in the literature [2,18]. In the spectrum of the stored $\mathrm{AB}$, there are additional peaks at $0-20 \mathrm{ppm}$, characteristic of borate anions. The narrow signal at ca. $2 \mathrm{ppm}$ refers to four-coordinated boron atoms, $\mathrm{BO}_{4}$. Broader components at low field shows a typical lineshape, arising from the central transition perturbed by second-order quadrupolar interactions that cannot be averaged under magic angle spinning conditions. This resonance is characterized by the quadrupole-coupling constant $Q_{c c}=2526 \mathrm{~Hz}$ and asymmetry parameter $\eta_{Q}=0.05$, and thus can be referred to planar triangle $\mathrm{BO}_{3}$ structures [19].

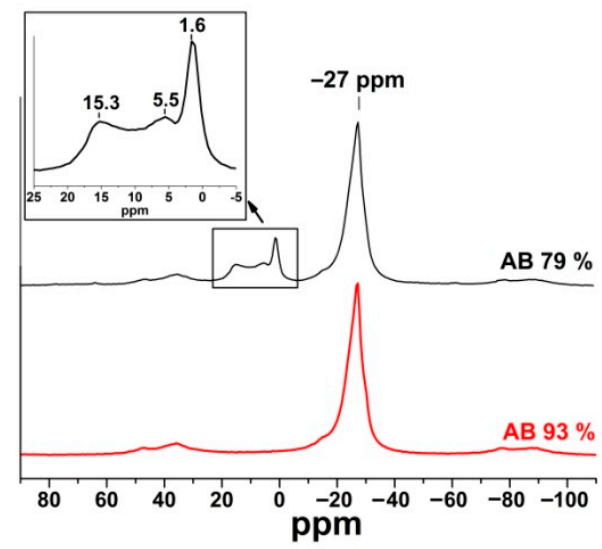

Figure 2. ${ }^{11} \mathrm{~B}$ MAS NMR data for samples of $\mathrm{NH}_{3} \mathrm{BH}_{3}$ with different purities.

The full interpretation of the composition and structure of the products forming in the AB storage is a difficult task. Note that one may expect formation of a series of compounds. The process of interaction of ammonia borane with water can be represented as follows [20-22]:

$$
\mathrm{NH}_{3} \mathrm{BH}_{3}+3 \mathrm{H}_{2} \mathrm{O} \rightarrow \mathrm{H}_{3} \mathrm{BO}_{3}+\mathrm{NH}_{3}+3 \mathrm{H}_{2} \uparrow \text {. }
$$

Therefore, there may take place formation of boric acid, including its dehydrogenated species, as well as of products of its interaction with ammonia-ammonium borates with different compositions and contents of crystallization water [23].

The ATR FTIR data are in full agreement with the results of the ${ }^{11} \mathrm{~B}$ MAS NMR spectroscopy. From Figure 3, it is seen that ammonia borane is, indeed, stable towards the action of moisture. The spectrum of the $\mathrm{AB}$ grains which were wetted by water and kept for 15 days in the open air at a 
humidity not higher than $15 \%$ practically coincides with the spectrum of the initial hydride described in $[2,24,25]$. Artificial ageing of ammonia borane by its longer contact with the open-air moisture (five months at a humidity of higher than $30 \%$ ) and by heating of water-wetted grains of $\mathrm{AB}$ led to the appearance of new absorption bands (a. b.) in the IR spectra of the samples. It should be noted that the set of the a. b., appearing upon the $\mathrm{AB}$ interaction with water, was the same in all cases under study, and was in full agreement with the additional absorption bands observed in the spectrum of the stored AB 79\% sample in Figure 3.

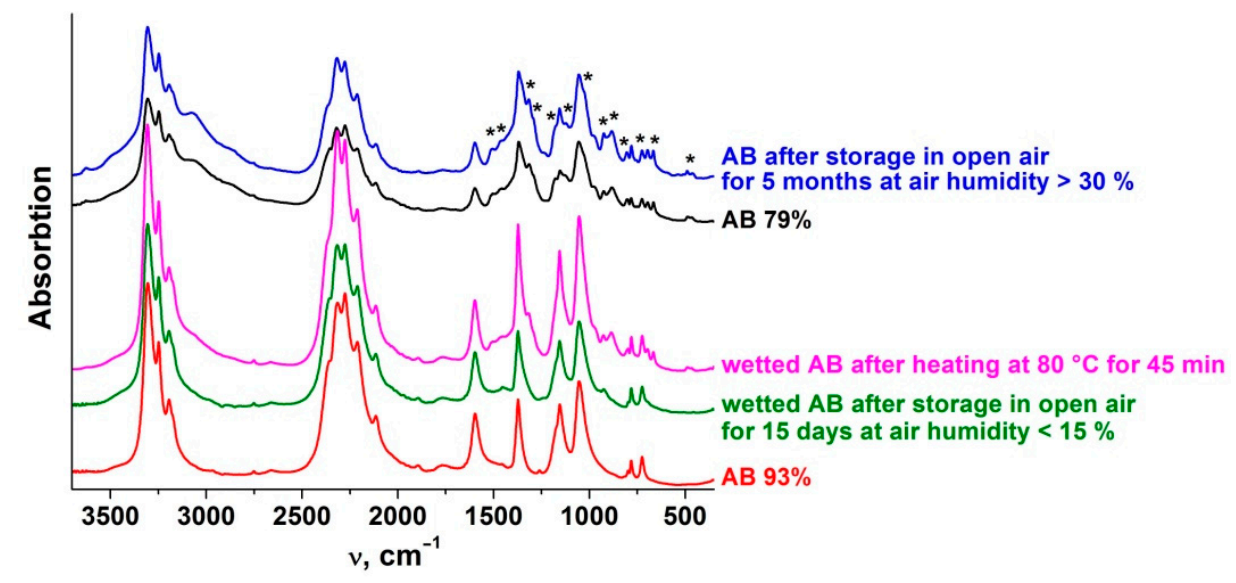

Figure 3. ATR FTIR spectra of samples of $\mathrm{NH}_{3} \mathrm{BH}_{3}$ interacting with water under different conditions, and of the samples of $\mathrm{NH}_{3} \mathrm{BH}_{3}$ of different purity. The absorption bands not belonging to $\mathrm{NH}_{3} \mathrm{BH}_{3}$ are marked by *.

From the analysis of the literature, it follows that these absorption bands are very consistent with the vibrations of borate anions of $\left(\mathrm{NH}_{4}\right)_{2} \mathrm{~B}_{8} \mathrm{O}_{13} \cdot 6 \mathrm{H}_{2} \mathrm{O}$ and monoclinic metaboric acid, which contain boron both with a three- and four-coordination of oxygen, shown in Table 1. Even if the boric acid does form, it is not the main impurity in Figure 4.

Table 1. Comparison of the absorption bands $\left(\mathrm{in}^{-1}\right.$ ) of the borate anions forming in the interaction of $\mathrm{NH}_{3} \mathrm{BH}_{3}$ with $\mathrm{H}_{2} \mathrm{O}$ with the spectra of the model compounds.

\begin{tabular}{|c|c|c|c|c|}
\hline $\begin{array}{c}\text { Borates } \\
\text { Absorption Bands }\end{array}$ & $\begin{array}{c}\mathrm{NH}_{4} \mathrm{~B}_{5} \mathrm{O}_{8} \cdot 4 \mathrm{H}_{2} \mathrm{O} \\
\left(\mathrm{B}_{(3)}-\mathrm{O}, \mathrm{B}_{(4)}-\mathrm{O}\right) \\
{[26]}\end{array}$ & $\begin{array}{c}\left(\mathrm{NH}_{4}\right)_{2} \mathrm{~B}_{8} \mathrm{O}_{13} \cdot 6 \mathrm{H}_{2} \mathrm{O} \\
\left(\mathrm{B}_{(3)}-\mathrm{O}, \mathrm{B}_{(4)}-\mathrm{O}\right) \\
{[26]}\end{array}$ & $\begin{array}{c}\mathrm{HBO}_{2} \text { Monoclinic } \\
\left(\mathrm{B}_{(3)}-\mathrm{O}_{1} \mathbf{B}_{(4)}-\mathrm{O}\right) \\
{[27]}\end{array}$ & $\begin{array}{c}\mathrm{HBO}_{2} \text { Cubic } \\
\left(\mathbf{B}_{(4)}-\mathrm{O}\right) \\
{[27]}\end{array}$ \\
\hline 1460 & $1436 \mathrm{~s}, \mathrm{~b}$ & $\begin{array}{l}1468 \mathrm{~s}, \mathrm{~b} \\
1398 \mathrm{~s}, \mathrm{~b}\end{array}$ & $\begin{array}{c}1485 \mathrm{sh} \\
1400 \mathrm{vs}, \mathrm{b}\end{array}$ & 1463 vs, b \\
\hline 1312 & $1351 \mathrm{~s}, \mathrm{~b}$ & $1346 \mathrm{~s}, \mathrm{~b}$ & $\begin{array}{l}1335 \mathrm{vs} \\
1318 \mathrm{sh}\end{array}$ & \\
\hline 1290 & $1238 \mathrm{~m}$ & & $\begin{array}{l}1290 \mathrm{sh} \\
1205 \mathrm{~s}\end{array}$ & \\
\hline $\begin{array}{l}1179 \\
1125\end{array}$ & & $\begin{array}{l}1182 \mathrm{~m} \\
1113 \mathrm{w}\end{array}$ & 1124 vs & 1183 vs, b \\
\hline $\begin{array}{l}975 \\
925\end{array}$ & $921 \mathrm{~s}$ & $\begin{array}{l}969 \mathrm{~m} \\
923 \mathrm{~s}\end{array}$ & $\begin{array}{l}980 \mathrm{w} \\
960 \mathrm{~m} \\
918 \mathrm{w}\end{array}$ & $\begin{array}{l}993 \text { vs, b } \\
945 \text { vs, b }\end{array}$ \\
\hline 881 & & $884 \mathrm{~m}$ & $877 \mathrm{~s}$ & $895 \mathrm{~m}, \mathrm{~b}$ \\
\hline 805 & $781 \mathrm{~s}$ & $806 \mathrm{~m}$ & $803 \mathrm{~m}$ & $825 \mathrm{vs}, \mathrm{b}$ \\
\hline 696 & $692 \mathrm{~s}$ & $696 \mathrm{~m}$ & $690 \mathrm{~m}$ & $680 \mathrm{sh}$ \\
\hline 665 & $642 \mathrm{~m}$ & $666 \mathrm{~s}$ & $\begin{array}{l}653 \mathrm{~m} \\
620 \mathrm{wv}\end{array}$ & $643 \mathrm{~s}, \mathrm{sh}$ \\
\hline 488 & $459 w$ & $486 \mathrm{~s}$, sh & $\begin{array}{l}481 \mathrm{~m} \\
443 \mathrm{~m} \\
423 \mathrm{~m}\end{array}$ & $\begin{array}{c}742 \mathrm{~s} \\
433 \mathrm{~m}, \mathrm{~b}\end{array}$ \\
\hline
\end{tabular}

${ }^{*} \mathrm{~s}=$ strong, $\mathrm{m}=$ medium, $\mathrm{w}=$ weak, $\mathrm{v}=$ very, $\mathrm{b}=$ broad, $\mathrm{sh}=$ shoulder. 


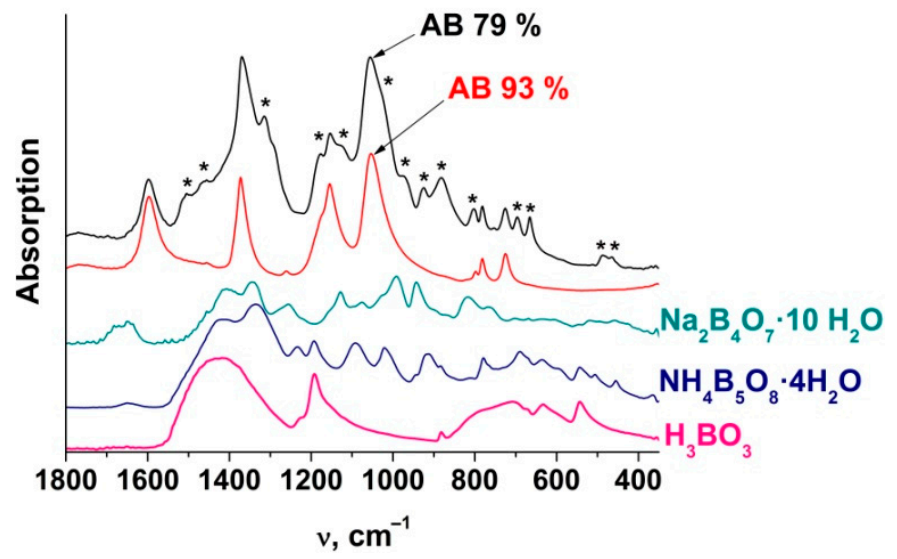

Figure 4. ATR FTIR spectra in the vibration region of borate anions for the sample of $\mathrm{NH}_{3} \mathrm{BH}_{3}$ with the 93 and 79\% purity, and of sodium and ammonium borates containing three- and four-coordinated boron, and boric acid. The absorption bands not belonging to $\mathrm{NH}_{3} \mathrm{BH}_{3}$ are marked by *.

Calculation of the kinetic parameters from the results of the thermal analysis may be considered as a universal and easily accessible method to compare reactivity of different samples of AB. In Figure 5, DTA curves for the samples of $A B$ under study are shown. The curves are in good agreement with those published in the literature $[3,8]$. As expected, the thermolysis of $A B$ begins with the endothermal stage of melting, during which ammonia borane isomerizes to DADB. Thanks to its ionic structure, DADB initiates the exothermal stage of dehydrogenation (1), during which there is the release of the first equivalent of $\mathrm{H}_{2}$ and the formation of polyaminoborane. At all rates of heating, the release of heat in stage (1) shows itself in the DTA curves as a relatively narrow peak with a clearly defined maximum. Therefore, these values can be conveniently used in the Kissinger Equation (4), in contrast to the broad peaks observed in the DTA curves for the subsequent process of dehydrogenation of polyaminoborane to polyiminoborane (2).

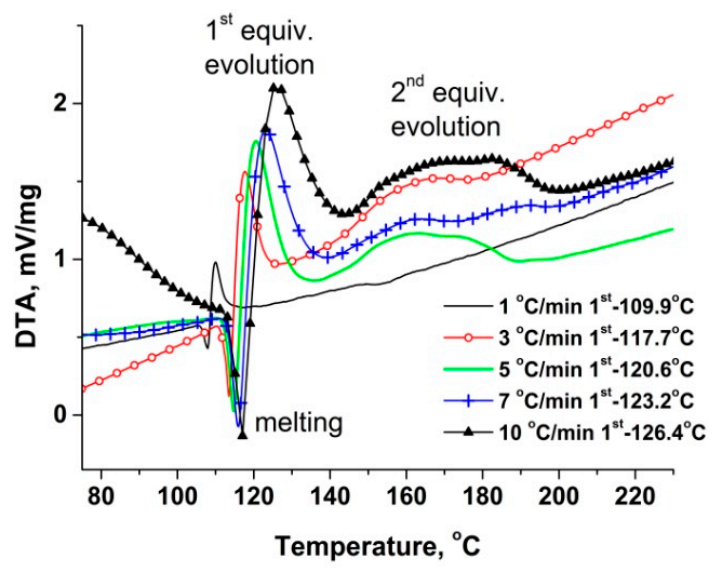

(a)

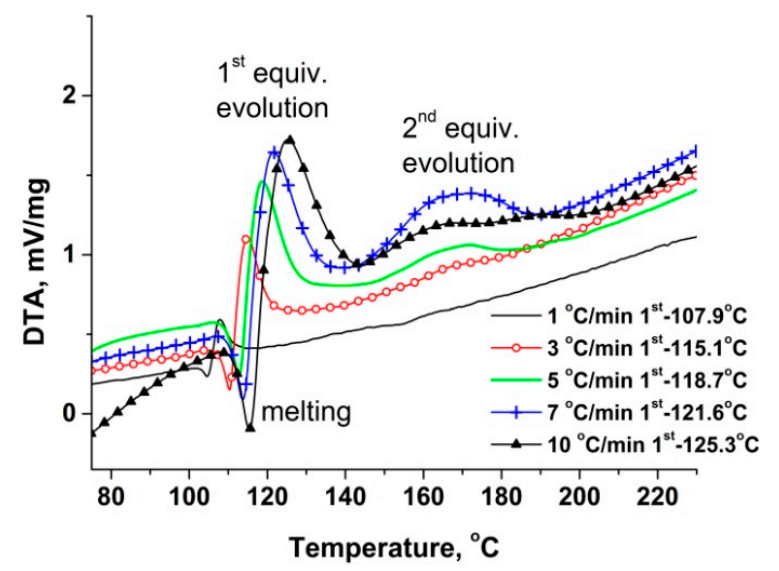

(b)

Figure 5. DTA curves for $93 \%$ (a) and $79 \%$ (b) pure samples of $\mathrm{NH}_{3} \mathrm{BH}_{3}$ obtained at the rates of heating from 1 to $10^{\circ} \mathrm{C} / \mathrm{min}$. Also shown are the temperatures of the maxima corresponding to the first stage of ammonia borane dehydrogenation (1).

In Figure 6, the linear dependences in the coordinates of the Kissinger Equation (4) are shown. The calculated values of the apparent activation energy $\left(E_{a}\right)$ for the samples $\mathrm{AB} 93 \%$ and $\mathrm{AB} 79 \%$ are $174 \pm 5 \mathrm{~kJ} / \mathrm{mol}$ and $163 \pm 7 \mathrm{~kJ} / \mathrm{mol}$, respectively. The values of the pre-exponential factor $\left(A_{0}, \mathrm{~min}^{-1}\right)$ are $8.30700 \times 10^{22}\left( \pm 0.1 \times 10^{6}\right)$ for $\mathrm{AB} 93 \%$ and $0.29295 \times 10^{22}\left( \pm 0.2 \times 10^{6}\right)$ for $\mathrm{AB} 79 \%$. Note that the values $E_{a} \sim 160-180 \mathrm{~kJ} / \mathrm{mol}$ have also been reported in other studies devoted to solid-state $\mathrm{AB}$ dehydrogenation [11,28-31]. The obtained values of the apparent energy of activation are in good 
agreement with the value of $161 \pm 7 \mathrm{~kJ} / \mathrm{mol}$ given in our previous study [14], where the kinetic curves of hydrogen release in the thermolysis of a mixture of $87 \%$ pure $A B$ with quartz sand under the isothermal conditions $\left(85-99^{\circ} \mathrm{C}\right)$ were described by the empirical Avrami-Erofeev Equation. Note that the calculated values of the activation energy for the monomolecular and intermolecular stages of dehydrogenation are 161.1 and $149.9 \mathrm{~kJ} / \mathrm{mol}$, respectively. These energy barriers exceed the energy needed for the cleavage of the B-N bond $(120.5 \mathrm{~kJ} / \mathrm{mol})$, which indicates that the reaction takes a complex pathway [5].

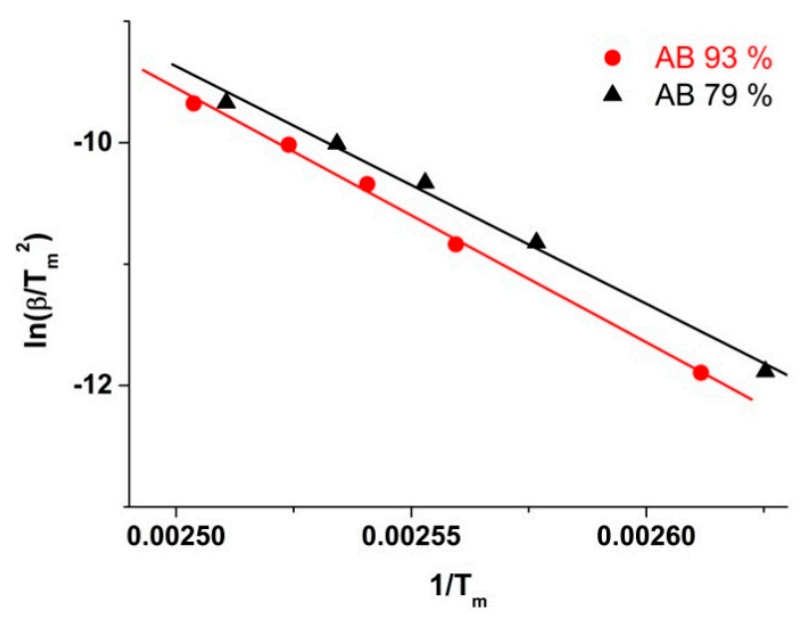

Figure 6. Linear dependencies in the coordinates of the Kissinger Equation (4) for samples of ammonia borane with different purities.

The values of $E_{a}$ obtained in this work indicate that the decrease in $\mathrm{AB}$ purity and the accumulation in it of the products of hydrolysis lead to a decrease in the apparent activation energy, which is consistent with the shorter induction period in the isothermal dehydrogenation of the stored AB 79\% in Figure 1 . Besides, the obtained results are in agreement with the previously published results, showing that the addition to $\mathrm{AB}$ of $\mathrm{H}_{3} \mathrm{BO}_{3}[9,32,33], \mathrm{B}_{2} \mathrm{O}_{3}$ [9] and $\mathrm{NH}_{4} \mathrm{~B}_{5} \mathrm{O}_{8} \cdot 4 \mathrm{H}_{2} \mathrm{O}$ [32] accelerates the process of its thermolysis. It should be noted that in [9], by using the Kissinger, Ozawa-Flynn-Wall, and ASTM (American Society for Testing and Materials) methods, a decrease in $E_{a}$ has been demonstrated for the thermolysis of a ball-milled mixture of $\mathrm{AB}$ with boric acid or boron oxide (50 wt \%). The value of $\mathrm{E}_{\mathrm{a}}$ for the neat $\mathrm{AB}$ was $\sim 120 \mathrm{~kJ} / \mathrm{mol}$, and after the addition of the dopants, it was decreased to $\sim 100$ $\mathrm{kJ} / \mathrm{mol}$. Thus, the value of $\mathrm{E}_{\mathrm{a}}$ was decreased by $\sim 15 \%$. In our case, the change in this value was by $\sim 6 \%$, which we believe was due to only a $14 \mathrm{wt} \%$ difference in the content of borate impurities between $\mathrm{AB}$ $79 \%$ and $\mathrm{AB} 93 \%$.

Note that at the rate of heating of $1{ }^{\circ} \mathrm{C} / \mathrm{min}$, which is preferable to achieve thermodynamically equilibrium states, the temperatures of melting for $\mathrm{AB} 79 \%$ and $\mathrm{AB} 93 \%$ are $104.5^{\circ} \mathrm{C}$ and $107.9^{\circ} \mathrm{C}$, respectively in Figure 5. It can be suggested that the presence of impurities with an ionic structure may have an influence on the polar dihydrogen bonds of the $A B$ crystal lattice, promoting their destabilization and reducing the melting temperature. This causes the $\mathrm{AB}$ isomerization to DADB to proceed at a faster rate and, hence, lead to a shorter induction period, and this did take place in Figure 1. Of course, this suggestion requires further investigation, including the use of quantum chemical calculations. It can only be said that boric acid is known from the literature to be capable of forming adducts via hydrogen bonds with amino groups of organic compounds [34].

We believe that the smaller value of $E_{a}$ for the neat $\mathrm{AB}$ may be determined not only by the $\mathrm{AB}$ purity, but also by the conditions of the thermolysis, where the material and design of the crucible, the drying of the gases, and the $\mathrm{AB}$ contact with moisture at the stage of weighing and the preparation of the experiment are also important. For example, it has been shown in [35] that the use of a copper crucible for the thermal analysis of $\mathrm{AB}$ had an influence on the process energy and led to $\mathrm{AB}$ oxidation to boric acid. Also, it has been reported in $[14,36]$ that increasing the heat conductivity of the reaction 
layer where the $\mathrm{AB}$ is decomposed led to a longer induction period and a reduction in the contribution of the side processes associated with the evolution, into the gas phase, of boron-containing impurities (borazine, diborane, and others). Apart from the material of the crucible, the size of the outlet hole through which the gas evolving from $\mathrm{AB}$ passes into the flow of the carrier gas also plays a role [37].

\section{Materials and Methods}

The sample of $\mathrm{NH}_{3} \mathrm{BH}_{3}$ with the purity of $93 \%$ ( $\mathrm{AB} 93 \%$ ) was prepared and characterized as described in [38]. According to $\mathrm{X}$-ray diffraction, the average size of the coherent scattering region was equal to $70 \mathrm{~nm}$. The sample of $\mathrm{AB}$ with the purity of $79 \%(\mathrm{AB} 79 \%)$ differed, in that it had been stored for 12 years in a desiccator which was periodically opened. The purity of the hydride was estimated experimentally by its catalytic hydrolysis in the presence of an active cobalt-boride catalyst, taking into account that one mole of ammonia borane gave three moles of hydrogen [39].

The $\mathrm{H}_{2}$ release during $\mathrm{AB}$ solid-state thermolysis was studied by the volumetric method at $100{ }^{\circ} \mathrm{C}$. The experimental set-up consisted of an oil bath with an RCT basic magnetic stirrer (IKA, Staufen, Germany) with an external IKATRON ETS-D4 Fuzzy temperature controller (IKA, Staufen, Germany), a $32 \mathrm{~mL}$ glass reactor equipped with a condenser and a thermocouple in a quartz jacket suitable for temperature measurements inside the solid reaction layer. A gas-collecting system with a trap filled with a $5 \mathrm{wt} \%$ water solution of $\mathrm{CuSO}_{4}$ was connected to a $100 \mathrm{~mL}$ gas burette with a resolution of $0.2 \mathrm{~mL}$, and $100 \mathrm{mg}$ of the $\mathrm{AB}$ sample was loaded into the reactor. The reactor was sealed and immersed into the oil bath, which was heated to the required temperature. The measured volume of hydrogen was corrected to n.t.p, taking into account the thermal expansion of the air inside the system. The data obtained was expressed in terms of $\mathrm{H}_{2}$ equivalents, the number of moles of $\mathrm{H}_{2}$ released from one mole of $\mathrm{AB}$.

Attenuated total reflection Fourier transform infrared spectroscopy (ATR FTIR) was performed on an Agilent Cary 600 (Agilent Technologies, Santa Clara, CA, USA) spectrometer equipped with a Gladi ATR (PIKE Technologies, Madison, WI, USA) attachment in the range of $300-4000 \mathrm{~cm}^{-1}$ without pretreatment of the samples. The reagents $\mathrm{H}_{3} \mathrm{BO}_{3}$ (GOST 9656-75, Reahim, Moscow, Russia), $\mathrm{Na}_{2} \mathrm{~B}_{4} \mathrm{O}_{7} \cdot 10 \mathrm{H}_{2} \mathrm{O}$ (GOST 4199-76, Ecros, St. Petersburg, Russia), and $\mathrm{NH}_{4} \mathrm{~B}_{5} \mathrm{O}_{8} \cdot 4 \mathrm{H}_{2} \mathrm{O}$ (CAS 12229-12-8, Vecton, St. Petersburg, Russia) were used as model compounds.

The thermal analysis of the compounds was made on a Netzsch STA 449 C Jupiter instrument equipped with a DTA/TG holder (NETZSCH, Selb, Germany) in the temperature range $20-300{ }^{\circ} \mathrm{C}$. The $\mathrm{AB}$ sample $(5 \mathrm{mg})$ was placed into an open alumina crucible and heated under a flow of dry He at a heating rate varying from 1 to $10^{\circ} \mathrm{C} / \mathrm{min}$.

The ${ }^{11} \mathrm{~B}$ magic angle spinning nuclear magnetic resonance (MAS NMR) spectra were collected with a Bruker Avance 400 spectrometer (Bruker, Billerica, MA, USA) operating at a Larmor frequency of $128.38 \mathrm{MHz}$. The samples were spun in $\mathrm{ZrO}_{2}$ rotors at $8 \mathrm{kHz}$. The pulse length of $6 \mu$ s was used corresponding to the $45^{\circ}$ pulse for a $\mathrm{H}_{3} \mathrm{BO}_{3}$ aqueous solution. For each spectrum, 80 scans were accumulated with a recycle delay of $10 \mathrm{~s}$. The chemical shifts were referenced to $\mathrm{NaBH}_{4}$ $(\delta=-41 \mathrm{ppm})$ as an external standard [16]. Spectra were simulated with the use of the Dominique Massiot's Fit (DMFIT) software [40].

\section{Conclusions}

The results of our study show that, in spite of its stability, the AB contact with the air moisture caused its slow hydrolysis, as well as the accumulation of three- and four-coordinated borate anions, typical of the borates of ammonium and metaboric acid. The full interpretation of the composition and structure of the forming impurity compounds is difficult because of their variety, different degrees of crystallinity, and the extent of hydration. It was shown that the impurities formed during the long storage of $\mathrm{AB}$, and its rapid heating at $80^{\circ} \mathrm{C}$ in the presence of water had identical compositions. Calculations of the thermal analysis data have shown that with the reduction in the AB purity from $93 \%$ to $79 \%$ during the 12 years of storage in a periodically opened desiccator, as calculated by 
the Kissinger Equation, there was a decrease in the apparent activation energy for the first stage of $\mathrm{AB}$ dehydrogenation (1) from 174 to $163 \mathrm{~kJ} / \mathrm{mol}$. In the case of the isothermal solid-state $\mathrm{AB}$ dehydrogenation, this presented itself in a shortening of the induction period.

The method of the thermal analysis can be considered as a universal and standardized approach to the estimation and comparison of the reactivity of samples of $A B$ studied by different research teams, where the values of the apparent activation energy will be compared. However, this will require a rather full description of the experimental conditions, and for the effect of $\mathrm{AB}$ purity on the calculated kinetic parameters to be taken into account.

Author Contributions: Conceptualization, O.V.K., O.V.N. and V.I.S.; Methodology and Formal Analysis, O.V.K. and O.V.N.; Investigation, A.M.O., G.V.O. and S.S.A.; Writing-Original Draft Preparation, O.V.K. and A.M.O.; Writing—review and editing, O.V.N.; Visualization, O.V.K., Supervision, V.I.S.

Funding: This work was supported by Ministry of Science and Higher Education of the Russian Federation (project AAAA-A17-117041710089-7).

Conflicts of Interest: The authors declare no conflict of interest. The funders had no role in the design of the study; in the collection, analyses, or interpretation of data; in the writing of the manuscript, or in the decision to publish the results.

\section{References}

1. Wang, P. Solid-state thermolysis of ammonia borane and related materials for high-capacity hydrogen storage. Dalt. Trans. 2012, 41, 4296. [CrossRef]

2. Demirci, U.B. Ammonia borane, a material with exceptional properties for chemical hydrogen storage. Int. J. Hydrog. Energy 2017, 42, 9978-10013. [CrossRef]

3. Baitalow, F.; Baumann, J.; Wolf, G.; Jaenicke-Rößler, K.; Leitner, G. Thermal decomposition of B-N-H compounds investigated by using combined thermoanalytical methods. Thermochim. Acta 2002, 391, 159-168. [CrossRef]

4. Frueh, S.; Kellett, R.; Mallery, C.; Molter, T.; Willis, W.S.; King'ondu, C.; Suib, S.L. Pyrolytic decomposition of ammonia borane to boron nitride. Inorg. Chem. 2011, 50, 783-792. [CrossRef] [PubMed]

5. Al-Kukhun, A.; Hwang, H.T.; Varma, A. Mechanistic studies of ammonia borane dehydrogenation. Int. J. Hydrog. Energy 2013, 38, 169-179. [CrossRef]

6. Petit, J.-F.; Demirci, U.B. Mechanistic insights into dehydrogenation of partially deuterated ammonia borane $\mathrm{NH}_{3} \mathrm{BD}_{3}$ being heating to $200^{\circ} \mathrm{C}$. Inorg. Chem. 2019, 58, 489-494. [CrossRef] [PubMed]

7. Nguyen, M.T.; Nguyen, V.S.; Matus, M.H.; Gopakumar, G.; Dixon, D.A. Molecular mechanism for $\mathrm{H}_{2}$ release from $\mathrm{BH}_{3} \mathrm{NH}_{3}$, including the catalytic role of the Lewis acid $\mathrm{BH}_{3}$. J. Phys. Chem. A 2007, 111, 679-690. [CrossRef]

8. He, T.; Xiong, Z.; Wu, G.; Chu, H.; Wu, C.; Zhang, T.; Chen, P. Nanosized Co- and Ni-catalyzed ammonia borane for hydrogen storage. Chem. Mater. 2009, 21, 2315-2318. [CrossRef]

9. Ergüven, H.; Kantürk Figen, A.; Pişkin, S. Ammonia borane-boron composites for hydrogen release: Thermolysis kinetics. Energy Sources Part A Recover. Util. Environ. Eff. 2017, 39, 613-617. [CrossRef]

10. Yang, Z.; Zhou, D.; Chen, B.; Liu, Z.; Xia, Q.; Zhu, Y.; Xia, Y. Improved hydrogen release from ammonia borane confined in microporous carbon with narrow pore size distribution. J. Mater. Chem. A 2017, 5 , 15395-15400. [CrossRef]

11. Gangal, A.C.; Sharma, P. Kinetic analysis and modeling of thermal decomposition of ammonia borane. Int. J. Chem. Kinet. 2013, 45, 452-461. [CrossRef]

12. Petit, J.-F.; Miele, P.; Demirci, U.B. Ammonia borane $\mathrm{H}_{3} \mathrm{~N}-\mathrm{BH}_{3}$ for solid-state chemical hydrogen storage: Different samples with different thermal behaviors. Int. J. Hydrog. Energy 2016, 41, 15462-15470. [CrossRef]

13. Keskin, E.; Coşkuner Filiz, B.; Kılıç Depren, S.; Kantürk Figen, A. Recommendations for ammonia borane composite pellets as a hydrogen storage medium. Int. J. Hydrog. Energy 2018, 43, 20354-20371. [CrossRef]

14. Simagina, V.I.; Vernikovskaya, N.V.; Komova, O.V.; Kayl, N.L.; Netskina, O.V.; Odegova, G.V. Experimental and modeling study of ammonia borane-based hydrogen storage systems. Chem. Eng. J. 2017, 329, 156-164. [CrossRef] 
15. Komova, O.V.; Simagina, V.I.; Kayl, N.L.; Odegova, G.V.; Netskina, O.V.; Chesalov, Y.A.; Ozerova, A.M. Improved low-temperature hydrogen generation from $\mathrm{NH}_{3} \mathrm{BH}_{3}$ and $\mathrm{TiO}_{2}$ composites pretreated with water. Int. J. Hydrog. Energy 2013, 38, 6442-6449. [CrossRef]

16. Shaw, W.J.; Bowden, M.; Karkamkar, A.; Howard, C.J.; Heldebrant, D.J.; Hess, N.J.; Linehan, J.C.; Autrey, T. Characterization of a new phase of ammonia borane. Energy Environ. Sci. 2010, 3, 796. [CrossRef]

17. Staubitz, A.; Robertson, A.P.M.; Manners, I. Ammonia-borane and related compounds as dihydrogen sources. Chem. Rev. 2010, 110, 4079-4124. [CrossRef]

18. Stowe, A.C.; Shaw, W.J.; Linehan, J.C.; Schmid, B.; Autrey, T. In situ solid state ${ }^{11}$ B MAS-NMR studies of the thermal decomposition of ammonia borane: Mechanistic studies of the hydrogen release pathways from a solid state hydrogen storage material. Phys. Chem. Chem. Phys. 2007, 9, 1831. [CrossRef]

19. Yamada, K. A solid-state NMR study of boric acid doped in poly(vinyl alcohol). In NMR Spectroscopy of Polymers: Innovative Strategies for Complex Macromolecules; Cheng, H.N., Asakura, T., English, A.D., Eds.; ACS Symposium Series; American Chemical Society: Washington, DC, USA, 2011; pp. 133-146. [CrossRef]

20. Liu, C.-H.; Wu, Y.-C.; Chou, C.-C.; Chen, B.-H.; Hsueh, C.-L.; Ku, J.-R.; Tsau, F. Hydrogen generated from hydrolysis of ammonia borane using cobalt and ruthenium based catalysts. Int. J. Hydrog. Energy 2012, 37, 2950-2959. [CrossRef]

21. Mohajeri, N.; T-Raissi, A.; Adebiyi, O. Hydrolytic cleavage of ammonia-borane complex for hydrogen production. J. Power Sources 2007, 167, 482-485. [CrossRef]

22. Chou, C.-C.; Lee, D.-J.; Chen, B.-H. Hydrogen production from hydrolysis of ammonia borane with limited water supply. Int. J. Hydrog. Energy 2012, 37, 15681-15690. [CrossRef]

23. Moussa, G.; Moury, R.; Demirci, U.B.; Miele, P. Borates in hydrolysis of ammonia borane. Int. J. Hydrog. Energy 2013, 38, 7888-7895. [CrossRef]

24. Yang, Z.; Wang, Y.; Liang, J.; Chen, J. Hydrogen releasing of lithium amidoborane- $\mathrm{LiNH}_{2} \mathrm{BH}_{3}$. Mater. Trans. 2011, 52, 651-653. [CrossRef]

25. Xie, S.; Song, Y.; Liu, Z. In situ high-pressure study of ammonia borane by Raman and IR spectroscopy. Can. J. Chem. 2009, 87, 1235-1247. [CrossRef]

26. Jiang, W.; Li-Xia, Z.; Shu-Ping, X.; Bo, W.; Shi-Yang, G. FTIR and Raman spectroscopic study of hydrated ammonium borates and their saturated aqueous solutions. Chem. J. Chin. Univ. 2004, 25, 1213-1217.

27. Bertoluzza, A.; Monti, P.; Battaglia, M.A.; Bonora, S. Infrared and raman spectra of orthorhombic, monoclinic and cubic metaboric acid and their relation to the "strength" of the hydrogen bond present. J. Mol. Struct. 1980, 64, 123-136. [CrossRef]

28. Gutowska, A.; Li, L.; Shin, Y.; Wang, C.M.; Li, X.S.; Linehan, J.C.; Smith, R.S.; Kay, B.D.; Schmid, B.; Shaw, W.; et al. Nanoscaffold mediates hydrogen release and the reactivity of ammonia borane. Angew. Chemie Int. Ed. 2005, 44, 3578-3582. [CrossRef]

29. Sepehri, S.; Garcia, B.B.; Cao, G. Tuning dehydrogenation temperature of carbon-ammonia borane nanocomposites. J. Mater. Chem. 2008, 18, 4034. [CrossRef]

30. Kang, X.; Fang, Z.; Kong, L.; Cheng, H.; Yao, X.; Lu, G.; Wang, P. Ammonia borane destabilized by lithium hydride: An advanced on-board hydrogen storage material. Adv. Mater. 2008, 20, 2756-2759. [CrossRef]

31. Si, X.; Sun, L.; Xu, F.; Jiao, C.; Li, F.; Liu, S.; Zhang, J.; Song, L.; Jiang, C.; Wang, S.; et al. Improved hydrogen desorption properties of ammonia borane by Ni-modified metal-organic frameworks. Int. J. Hydrog. Energy 2011, 36, 6698-6704. [CrossRef]

32. Komova, O.V.; Kayl, N.L.; Odegova, G.V.; Netskina, O.V.; Simagina, V.I. Destabilization of $\mathrm{NH}_{3} \mathrm{BH}_{3}$ by water during hydrothermolysis as a key factor in the high hydrogen evolution rates. Int. J. Hydrog. Energy 2016, 41, 17484-17495. [CrossRef]

33. Hwang, H.T.; Varma, A. Effect of boric acid on thermal dehydrogenation of ammonia borane: Mechanistic studies. Int. J. Hydrog. Energy 2013, 38, 1925-1931. [CrossRef]

34. Roy, A.; Choudhury, A.; Rao, C.N.R. Supramolecular hydrogen-bonded structure of a 1:2 adduct of melamine with boric acid. J. Mol. Struct. 2002, 613, 61-66. [CrossRef]

35. Butlak, A.V.; Kondrat'ev, Y.V.; Timoshkin, A.Y. Determination of the enthalpy of ammonia borane sublimation. Russ. J. Gen. Chem. 2014, 84, 2455-2456. [CrossRef]

36. Mohajeri, N.; T-Raissi, A.; Ramasamy, K.K. Thermal conductivity of ammonia borane complex and its composites with aluminum powder. Thermochim. Acta 2007, 452, 28-30. [CrossRef] 
37. Petit, J.-F.; Demirci, U.B. Discrepancy in the thermal decomposition/dehydrogenation of ammonia borane screened by thermogravimetric analysis. Int. J. Hydrog. Energy 2019, 44, 14201-14206. [CrossRef]

38. Gorlova, A.M.; Kayl, N.L.; Komova, O.V.; Netskina, O.V.; Ozerova, A.M.; Odegova, G.V.; Bulavchenko, O.A.; Ishchenko, A.V.; Simagina, V.I. Fast hydrogen generation from solid $\mathrm{NH}_{3} \mathrm{BH}_{3}$ under moderate heating and supplying a limited quantity of $\mathrm{CoCl}_{2}$ or $\mathrm{NiCl}_{2}$ solution. Renew. Energy 2018, 121, 722-729. [CrossRef]

39. Ozerova, A.M.; Bulavchenko, O.A.; Komova, O.V.; Netskina, O.V.; Zaikovskii, V.I.; Odegova, G.V.; Simagina, V.I. Cobalt boride catalysts for hydrogen storage systems based on $\mathrm{NH}_{3} \mathrm{BH}_{3}$ and $\mathrm{NaBH}_{4}$. Kinet. Catal. 2012, 53, 511-520. [CrossRef]

40. Massiot, D.; Fayon, F.; Capron, M.; King, I.; Le Calvé, S.; Alonso, B.; Durand, J.-O.; Bujoli, B.; Gan, Z.; Hoatson, G. Modelling one- and two-dimensional solid-state NMR spectra. Magn. Reson. Chem. 2002, 40, 70-76. [CrossRef]

(C) 2019 by the authors. Licensee MDPI, Basel, Switzerland. This article is an open access article distributed under the terms and conditions of the Creative Commons Attribution (CC BY) license (http://creativecommons.org/licenses/by/4.0/). 